\title{
Dinâmicas do consumo de bens virtuais: práticas e valores no universo de League of Legends ${ }^{1}$
}

\section{Tarcízio Macedo e Manuela do Corral Vieira}

\section{Resumo}

Este artigo busca compreender 0 consumo de bens virtuais nas práticas cotidianas de jogadores do jogo on-line League of Legends (LoL) para refletir sobre a própria constituição social dos consumidores desse jogo on-line. 0 objeto de estudo centrou-se nas skins disponíveis em $L o L$, as quais foram especificamente observadas nas relações estabelecidas com os jogadores e suas motivações de aquisição e interpretação desses bens no ambiente do jogo. 0 arcabouço teórico-analítico parte da orientação da abordagem antropológica do consumo. Como recorte empírico, a discussão será evidenciada por meio de uma pesquisa com premissas etnográficas com um grupo de consumidores de League of Legends das cidades de Belém (PA), Diadema (SP) e 0sasco (SP). As reflexões indicam que as motivações principais para 0 consumo dessas mercadorias em League são baseadas na atuação essencial dos valores simbólicos em detrimento dos valores de uso e de troca.

\section{Palavras-Chave}

Consumo. Bens virtuais. Jogo digital.

Tarcízio Macedo | tarcizio.macedo@bol.com.br

Mestre em Ciências da Comunicação pelo Programa de Pós-Graduação Comunicação, Cultura e Amazônia da Universidade Federal do Pará UFPA, Brasil. Pesquisador do Grupo Consia/UFPA.

\section{Manuela do Corral Vieira ।}

manuelacorralv@yahoo.com.br Doutora em Antropologia pela UFPA. Professora do Programa de PósGraduação Comunicação, Cultura e Amazônia da UFPA. Líder do Grupo de Pesquisa Consia/UFPA.

\section{Introdução²}

A venda de itens virtuais por dinheiro "real" é cada vez mais usada como modelo de receita em serviços e jogos on-line. Em vista disto, a partir de uma pesquisa que compreende 0 consumo como fato social, o objetivo deste artigo é apresentar parte dos resultados de um estudo que consistiu em analisar as dinâmicas que envolvem o consumo e o papel do que se convencionou chamar de "bens virtuais de consumo" ${ }^{3}$ na construção de relações de valores, hierarquias, diferenciações, significados e ressignificados desses objetos ${ }^{4}$ no ambiente do jogo on-line conhecido como League of Legends ${ }^{5}$ (LoL). Em 2016, LoL liderou 0 ranking dos jogos on-line mais lucrativos após estimativas de que atingiria a marca de U $\$ 1,8$ bilhão, o equivalente a U $\$ 150$ milhões por mês ${ }^{6}$, economia essa que se deve, sobretudo, à venda de itens virtuais no jogo.

0 jogo em questão é um Multiplayer Online Battle Arena (MOBA) ${ }^{7}$, um tipo de jogo do gênero competitivo de disputa territorial, que 
combina elementos de estratégias em tempo

real e torres de defesa. Em League, dois

times, de cinco jogadores cada, enfrentam-se

em um campo de batalha com a finalidade de

destruir a base adversária. 0 MOBA baseia-se

em um domínio player versus player ${ }^{8}(P v P)$,

no qual a prática do combate entre jogadores

é um fundamental ponto responsável pelas

decisões de game design (desenvolvimento do jogo) a partir das quais os comportamentos

desenvolvem-se, tanto em relação à interação

quanto à jogabilidade ${ }^{9}$ Q Qualquer incursão

a um servidor disponível do MOBA vai

demonstrar que uma série de elementos do

jogo atende a dinâmicas características do que

Roger Caillois (1990) identificaria como da

categoria agôn, típica de jogos competitivos e

de perícia, em que, na hora do jogo, na maioria

Uma primeira versão deste artigo foi apresentada na segunda reunião do GP de Games durante o XVII Encontro dos Grupos de Pesquisa em Comunicação, evento componente do $40^{\circ}$ Congresso Brasileiro de Ciências da Comunicação (Intercom), realizado na Universidade Positivo entre 04 a 09 de setembro de 2017, em Curitiba - PR. Esta versão preliminar foi selecionada pelo GP de Games como o melhor trabalho de mestrado e indicada para concorrer ao Prêmio Francisco Morel 2018 da Intercom.

Agradecemos ao financiamento da Coordenação de Aperfeiçoamento de Pessoal de Nível Superior (CAPES) para a realização deste estudo, bem como aos pareceristas anônimos da revista E-Compós por seus comentários amplos e construtivos, cujas observações e sugestões contribuíram substancialmente para o refino de diversos pontos deste artigo.

Trata-se de itens que são disponibilizados exclusivamente em ambientes digitais. Aprofundaremos o conceito posteriormente.

Objeto, neste estudo, é compreendido, tal como argumenta lan Woodward (2007, p. 3, tradução nossa), como "[...] coisas materiais que as pessoas encontram, interagem e usam" - tradução do original: "[...] material things people encounter, interact with and use". Trata-se de um componente discreto que é percebido pelo tato ou pela visão. Segundo o autor, os objetos têm diversas variações em escalas e tamanhos; neste artigo, específicamente, referem-se aos bens virtuais de consumo visualizáveis em LoL, sem uma dimensão física concreta. Para Georg Simmel (2004), um objeto refere-se a um agregado de qualidades detentoras de valores.

Trata-se de um jogo gratuito em ambiente digital on-line, exclusivo para computadores, criado pela desenvolvedora estadunidense Riot Games. É considerado o jogo mais jogado do mundo, com um alcance global que ultrapassou a marca de 100 milhões de jogadores ativos mensalmente em 2016 (MACEDO; VIEIRA, 2017a). Usaremos quatro termos para nos reportarmos ao jogo League of Legends deste momento em diante: seu gênero, o próprio título do jogo, seu acrônimo LoL ou simplesmente League. Os vocábulos, portanto, devem ser assim compreendidos como sinônimos, na maioria dos casos, exceto quando demarcado distintamente no texto. 0 jogo, desde 2012, tem uma versão nacional localizada no Brasil e um escritório filial em São Paulo capital.

Disponível em: <https://g00.gl/JL3Ss3> e <https://goo.gl/DDdaG4>. Acesso em: 15 jan. 2017.

A princípio, é preciso reforçar que a definição de uma espécie de taxonomia para os jogos digitais não é uma tarefa fácil e tem sido extensamente discutida por diversos autores dos Game Studies. MOBA, em livre tradução arena de batalhas on-line para vários jogadores, é um gênero de jogo de estratégia competitivo que incorpora elementos de jogos de ação. Consiste, basicamente, em um jogo de dois times competindo entre si em um mesmo mapa, no qual cada jogador controla somente um personagem escolhido no início da partida (MACEDO; AMARAL, 2015). A partir de 2010, tornou-se bastante popular.

Em tradução literal, jogador contra jogador.

Segundo Katie Salen e Eric Zimmerman (2004), jogabilidade é interação que ocorre entre jogadores e regras de um sistema formalizado por meio do jogo, ou seja, o ato de jogar. Para Espen Aaarseth (2003), jogabilidade compreende as ações, estratégias, relações sociais, comunicação intrapersonagem e interpersonagens, conhecimento dos jogadores, motivos dos jogadores etc. 
dos casos, os jogadores necessitam de um aspecto muito mais mecânico ${ }^{10}$.

Embora 0 elemento funcional ou instrumental ${ }^{11}$ seja basilar da experiência agnóstica que incute no jogo, estando a competição e a maestria como mecanismos centrais no MOBA, ele também requisita do jogador ações de cooperação e sociação, seja para que jogadores possam trabalhar em equipe para alcançar a vitória em uma partida, seja por meio do envio de presentes virtuais, ferramentas de bate-papo, fóruns, comunidades etc. Dentro de League, há uma variedade de bens virtuais; contudo, o foco deste estudo concentra-se em um tipo específico denominado como "skins"12, uma vez que estes itens extra, opcionais, foram considerados por todos os interlocutores deste estudo como 0 motivo principal para compras.

Na literatura sociológica e cultural do consumo, três perspectivas-chave são passíveis de serem identificadas a respeito dos usos dos bens na sociedade, o que concerne aos seguintes aspectos: funcionais, emocionais (hedônicos) e marcadores para desenhar distinções sociais (FEATHERSTONE, 1995). Sociólogos contemporâneos, como Mike Featherstone (1995), têm reivindicado a relevância dos aspectos emocionais individuais do consumo, uma vez que os percebe como um processo também hedonista que envolve a busca pelo prazer, 0 qual os consumidores procuram pelas sensações prazerosas ao misturarem estilos de consumo. Nesta abordagem, a estética, 0 visual e o prazer são trazidos à tona enquanto elementos que incorporam atributos nos bens.

Por outro lado, um número exponencial de trabalhos na sociologia do consumo procura lidar com o uso de bens na constituição de distinções e vínculos sociais (LEHDONVIRTA, 2009). De maneira ampla, os consumidores são identificados enquanto comunicadores que utilizam significados

100 termo "mecânica" diz respeito a uma lógica que rege os jogos, ou seja, suas regras. Uma variedade de atividades em League são subscritas às mecânicas internas ao próprio MOBA, implementadas em seu sistema por meio de regras. Nessa perspectiva, as interações entre os jogadores e 0 sistema decorrem conforme uma mecânica determinada: uma série de regras que são levadas em conta, necessariamente, mesmo que estas desapareçam gradativamente à medida que um jogador se familiariza com elas (FALCÃ0, 2014). Em LoL, particularmente, ter mecânica é saber jogar com um personagem com precisão.

110 jogo instrumental, geralmente, tem o foco na eficiência e na orientação instrumental para o aparato, no compromisso com 0 entendimento das estruturas e sistemas de jogo subjacentes, na definição de objetivos dinâmicos, no domínio e na perícia acerca dos aspectos técnico-operacionais, no desenvolvimento de expertise e uma proficiência técnica e de habilidades (TAYLOR, 2003).

12 Segundo Macedo e Amaral (2015) e Macedo e Vieira (2017a), skins são itens percebidos como adereços que procuram modificar e diferenciar a experiência dos jogadores com um personagem. Tratam-se de designs customizados com transformações estéticas de personagens dentro do ambiente do jogo. Diferentes personagens possuem distintos tipos de skins, que variam conforme classe, preço, valor e características. Neste estudo, ao nos reportarmos à expressão "bem virtual", estamos nos circunscrevendo a esse tipo de mercadoria no âmbito de LoL. 
simbólicos imbuídos em mercadorias para expressar classes, status, associações a grupos (semelhanças), diferenças ou autoexpressões (SIMMEL, 1904/1957; WOODWARD, 2007; VEBLEN, 2007; DOUGLAS; ISHERWOOD, 2013, dentre outros). Nesses casos, a satisfação derivada dos bens encontra-se, principalmente, conectada no que diz respeito à sua utilização como marcadores e, somente de modo secundário, relacionada ao seu consumo físico.

Desta maneira, usando essas noções como um ponto inicial para problematizar nossa proposta, tomamos como premissas as ideias de que:

a) 0 consumo é palco da diferença, sendo uma atividade realizável a partir de um sistema classificatório simbólico ${ }^{13}$ (ROCHA, 2000; ROCHA; AUCAR, 2014; DOUGLAS; ISHERWOOD, 2013, dentre outros) disposto coletivamente, no qual produtos, objetos, serviços e pessoas encontramse em interação recíproca para estabelecer a significação, constituindo parte de um jogo que organiza amplamente a visão de mundo (ROCHA; AUCAR, 2014);

b) um bem pode ser compreendido como um objeto ou produto de posse, de domínio de alguém ou de um determinado agrupamento, que possui serventia e/ou valor, o que o torna importante, mesmo de modo simbólico (REBS, 2012). Bens de consumo são também responsáveis por expressarem o lugar dos sujeitos no mundo social, aquele que é próximo ou distante; são capazes de manifestarem os interiores, desejos ou sentimentos e, simultaneamente a essa dinâmica, exporem as relações dos próprios bens entre si mesmos (ROCHA; AUCAR, 2014). Ademais, o conteúdo simbólico não se trata de uma característica inerente aos bens, mas um atributo da realidade social circundante. Logo, bens consumidos são capazes de articularem distinções sociais, o que permite que hierarquias de status se formem entre jogadores.

Para tanto, foi realizado estudo de viés etnográfico com um grupo de consumidoresjogadores de $L o L$ das cidades de Belém (PA), Diadema (SP) e Osasco (SP), sobre as percepções do consumo de bens virtuais por eles: as diferentes significações que adquirem pelos jogadores. A investigação desse universo procurou concentrar-se em analisar e compreender as motivações dos jogadores na compra e no uso de bens virtuais do tipo skin, os quais serão detalhados e analisados mais adiante, além de desvendar parte dessa genealogia de significados e valores atribuídos às mercadorias virtuais em League. 


\section{Notas metodológicas}

Thomas Apperley e Darshana Jayemane, no que diz respeito ao uso de abordagens ou métodos etnográficos, argumentam que "[...] fornecem aos estudos de jogo uma maneira de conectar objetos a práticas e de entender essas práticas em relação às vidas e experiências das pessoas que as representam"13 (APPERLEY; JAYEMANE, 2012, p. 8). Assim, os autores argumentam que a etnografia é uma valiosa abordagem para os Game Studies, pois permite reconhecer os complexos contextos nos quais o jogo se desenvolve, além de proporcionar uma estratégia vantajosa para compreender as distintas maneiras pelas quais um determinado jogo individual pode ser jogado, "não apenas em termos de execução estrutural do algoritmo, mas em termos de diversas respostas afetivas, culturais e situadas" (Idem, p. 10) ${ }^{14}$.
Neste sentido, a pesquisa de campo foi realizada por meio de estudo etnográfico efetivado com jogadores de $L o L$ e divide-se em duas etapas. Primeiramente, para contato com possíveis interlocutores, fizemos uso de um perfil no jogo e no site de rede social Facebook, particularmente, com 0 intento de sondar grupos de jogadores de League em Belém (PA), utilizando nossas próprias redes de contato ${ }^{15}$. Como segunda etapa, realizamos entrevistas semiestruturadas presencialmente com três dos cinco interlocutores em Belém (PA), e outras duas via chamada de vídeo, pelo aplicativo Skype, com jogadores das cidades de 0sasco (SP) e Diadema (SP). As entrevistas duraram cerca de duas horas cada, em média, e foram executadas durante os meses de dezembro de 2016, janeiro de 2017 e junho de $2017^{16}$. No decorrer das entrevistas, 0 roteiro foi adaptado conforme 0 desenvolvimento das respostas e as posições dos jogadores a respeito dos assuntos discutidos.

13 Tradução do original: "[...] provide game studies with a way of connecting objects to practices, and understanding those practices in relation to the lives and experiences of the people who enact them".

14 Tradução do original: "not simply in terms of structural execution of the algorithm, but in terms of diverse affective, cultural and situated responses".

15 A opção de escolhermos informantes que pertencessem a nossas redes fundamenta-se por se tratar de um estudo exploratório. Entretanto, por evadir ao escopo da discussão atual, caminharemos ao largo do aprofundamento das questões metodológicas e, por consoante, as implicações acarretadas por uma escolha de informantes "familiares", o que, como em qualquer outra opção, sabemos que implica ganhos e perdas. Ademais, a escolha por informantes dos estados do Pará e São Paulo não foi intencional, ou seja, não buscou evidenciar maneiras típicas de consumir em diferentes estados do Brasil, fato este confirmado quando, no trabalho de campo, percebemos que a categoria "territorialidade" não retornou como sendo considerada relevante para delimitar o consumo dos jogadores no ambiente de League.

16 Embora conversas mais informais de voz (via aplicativos de conversa como Skype e TeamSpeak, ou por escrito, pelos serviços de bate-papo do próprio jogo e de sites de redes sociais ou aplicativos de mensagens instantâneas) também façam parte do processo de construção de uma relação baseada na confiança entre os interlocutores e datem há muito mais tempo, na qual foi requisitado aos pesquisadores participarem de partidas e explorarem o universo do próprio jogo junto com os informantes. 
Portanto, após termos procurado delimitar interlocutores que jogam ou jogaram League of Legends, selecionando quais seriam nossos interlocutores, construímos as perguntas com base em eixos que focam em uma abordagem antropológica sobre as práticas e dinâmicas de consumo em $L o L$, responsáveis por guiar as entrevistas em um roteiro semiestruturado. Chegamos a cinco interlocutores, conforme sistematizado no quadro 1.

Todos os interlocutores tinham conhecimento dos objetivos da pesquisa, e os dados obtidos da etnografia, aqui inseridos, estão constituídos por meio de nomes fictícios baseados nos personagens do jogo de que mais gostavam, com o objetivo de preservar as identidades dos participantes para divulgação do estudo.

\section{Definindo bens virtuais de consumo}

A definição do que se compreende por "bens virtuais" tem sido um desafio durante a curta história do conceito. Muitos autores (RECUER0, 2010; REBS, 2012, dentre outros) procuram definir bens virtuais, embora se baseando somente nos serviços e plataformas que investigam ${ }^{17}$. Nesse sentido, a assertiva recorrente remete à ideia de que "bens virtuais são bens que existem em um mundo virtual" (LEHDONVIRTA, 2009, p. 99) ${ }^{18}$.

Quadro 1: Interlocutores da pesquisa

\begin{tabular}{|c|c|c|c|}
\hline Jogador (a) & Idade & Tempo de LoL & Cidade \\
\hline Draven & 18 anos & Joga há três anos e meio. & Osasco/SP \\
\hline Braum & 25 anos & Joga há quatro anos. & Belém/PA \\
\hline Jinx & 22 anos & Jogou durante dois anos, parou há nove meses. & Belém/PA \\
\hline Talon & 26 anos & Joga há três anos. & Diadema/SP \\
\hline Lulu & 23 anos & Joga há dois anos. & Belém/PA \\
\hline
\end{tabular}

Fonte: Elaborado pelos autores

17 Embora exista uma literatura considerável que se dedica aos estudos do consumo de bens virtuais utilizando a teoria dos capitais, de autores como Pierre Bourdieu, James Coleman e Robert Putnam, cujas contribuições são inegáveis, vale destacar que caminharemos por uma abordagem cultural e simbólica distinta. No Brasil, essa discussão pode ser obtida no debate realizado nos trabalhos de Raquel Recuero (2010) e Rebeca Rebs (2012), por exemplo.

18 Tradução do original: "virtual goods are goods that exist in a virtual world". 0 uso do termo "mundo virtual" nessa definição é, entretanto, discutível, de modo que acreditamos ser mais útil pensar na perspectiva de ambientes digitais do que necessariamente nessa categoria limitadora do conceito, uma vez que não se pode classificar League como sendo um mundo virtual, por não dispor de um ambiente persistente, sejam os personagens, seja o próprio jogo, além de outros elementos, conforme discutimos anteriormente (cf. MACED0; AMARAL, 2015). 
Para Juho Hamari e Vili Lehdonvirta (2010), o chamado mercado de bens virtuais, especificamente o modelo de receita de microtransações, envolve a venda de determinados tipos de itens virtuais, moedas ou personagens para os usuários de um serviço on-line $e^{19} .0$ dinheiro "real" trocado por moedas virtuais em um jogo digital permite, então, que o jogador possa trocar por itens virtuais no ambiente de determinado jogo. "Os itens podem variar de armas e armaduras em jogos online para roupas em mundos virtuais e emblemas gráficos bidimensionais simples em sites de redes sociais" (HAMARI; LEHDONVIRTA, 2010, p. $15)^{20}$. Neste artigo, ao usarmos o termo "bens virtuais" referimo-nos a um conjunto de ativos virtuais que podem ser produzidos em massa e, consequentemente, são com frequência comprados e vendidos como mercadorias de consumo convencionais (LEHDONVIRTA, 2009). Na prática, isso inclui principalmente uma variedade de itens disponíveis ao jogador por meio da venda de itens, personagens, RPs (moeda virtual de $L o L^{21}$ ) ou artigos dentro do próprio jogo (figura 1), como as skins, as quais serão o enfoque desta pesquisa.

Segundo Rebeca Rebs (2012, p. 207), bens virtuais são "itens ou elementos formados por pixels que vinculam valores capitais para a sua aquisiçãa”. Ainda assim, esses objetos podem ser compreendidos de forma única e independente, de acordo com os valores que incutirão em cada sujeito, uma vez que cada jogador cria códigos e critérios para valorizar, de forma tangível (econômica) ou intangível (subjetiva). Seguindo esta análise, o consumo passa a ser visto como um processo de envolvimento com as mercadorias (objetos em jogo), momento este em que os sujeitos utilizam objetos como uma práxis no mundo. Nessa perspectiva, as mercadorias incidem, simultaneamente, nas práticas cotidianas e na construção de sentidos em jogo.

Assim, a apropriação interativa desses produtos dependerá das dinâmicas destes ambientes particulares e seus gêneros específicos, desde itens funcionais, decorativos até simbólicos, estando relacionados diretamente com 0 valor

19 Neste sentido, a perspectiva dos autores compreende uma definição mais geral, deliberadamente abrangente do conceito, ao englobar não apenas jogos digitais, mas também, potencialmente, ampliar o espectro categórico que permite a inserção de outras transações de comércio digital.

20 Tradução do original: "The items can range from weapons and armour in online games to clothes in virtual worlds and simple two-dimensional graphical badges in social networking sites".

21 Em League, até o momento da presente pesquisa, há três tipos de moedas virtuais: (i) Influence Points (IP), uma forma de recompensar jogadores por partidas jogadas, usadas para efetuar trocas, dentro da loja do jogo, por personagens, itens para mecânicas, etc.; (ii) ouro, moedas coletadas por jogadores durante as partidas, ao abaterem inimigos, completarem objetivos e conquistarem metas, sendo usadas para aperfeiçoar os personagens durante as partidas em LoL; por fim, existem os (iii) Riot Points (RPs), uma moeda usada exclusivamente para liberar bens virtuais específicos, sendo adquiridas com dinheiro. 
Figura 1: Loja para aquisição de itens extra opcionais (skins, ícones, emotes, dentre outros) no MOBA League of Legends ${ }^{22}$

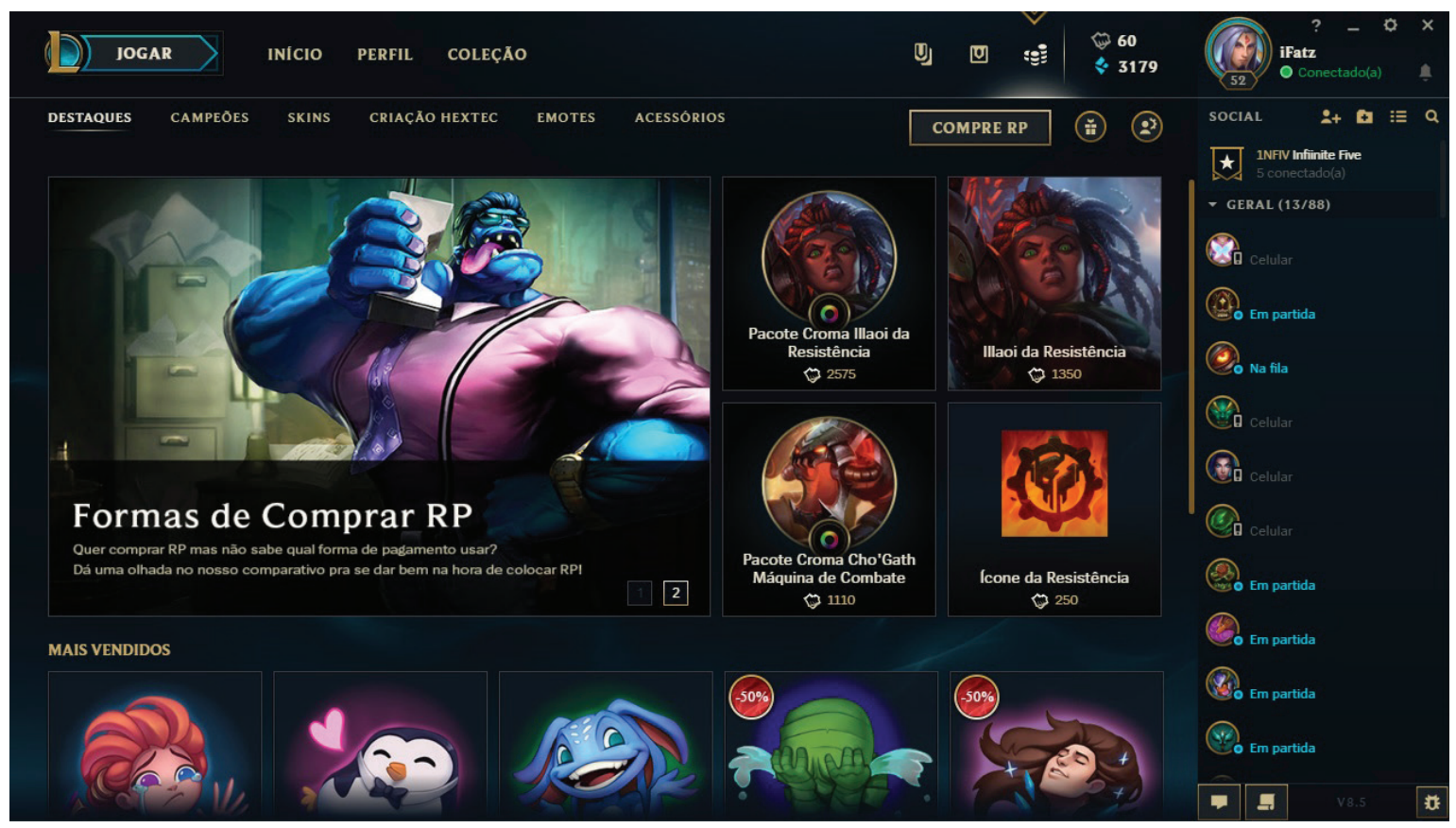

Fonte: Elaborado pelos autores; print screen da tela do jogo League of Legends BR

criado e distribuído nessas ambiências pelos sujeitos (RECUER0, 2010, on-line). Mesmo que um objeto tenha um valor indutivo coletivo, ainda assim há uma contrapartida subjetiva que pode dar usos e atributos completamente distintos da dinâmica pertencente a esse objeto. Como argumenta Georg Simmel (2005, p. 60), a chave para a compreensão do valor reside numa região em que "essa subjetividade é apenas provisória e, com efeito, não muito essencial"²3, uma vez que, para 0 autor, um mesmo objeto (neste caso, podemos pensar na skin) pode assumir maior ou menor grau de valor para uma ou para outra pessoa, e vice-versa, não estando vinculado permanentemente a um objeto da mesma forma que a cor e a temperatura.

Assim, o valor nunca é tido como uma "qualidade" dos objetos, mas sim um julgamento sobre eles que se mantém inerente ao sujeito: entretanto, nem o próprio significado mais profundo do conceito de valor, nem para a vida mental do sujeito, para os eventos sociais práticos ou arranjos baseados nestes, é suficientemente necessário para que

Foram realizadas intervenções nessa imagem, cujo objetivo foi de preservar as informações dos sujeitos que figuram na lista de amigos do perfil criado para adentrar no MOBA.

23 Tradução do original: "that subjectivity is only provisional and actually not very essential". 
se compreenda ao se referir determinado valor de um dado sujeito, porque até eles podem mudar (SIMMEL, 2005). Nesse sentido, entender a circulação dos tipos de bens virtuais em cada jogo digital requer uma percepção de como os sujeitos apropriam-se desses jogos e geram tipos de valores que são relevantes para os jogadores ali presentes, o que pressupõe a existência de diferenças de bens de consumo para cada grupo/comunidade.

No âmbito dessa discussão, contudo, a empresa constitui-se como um ator que não deve ser desconsiderado, uma vez que suas ações interferem diretamente no funcionamento desses ambientes e, consequentemente, do seu consumo. 0 tipo de modelo de negócio adotado em League, um jogo grátis para jogar (freeto-play) com compras opcionais, contrasta com outras abordagens em relação às receitas baseadas em microtransações (no caso de jogos para sites de redes sociais digitais e dispositivos móveis) e dos MMOs ${ }^{24}$ assentados em assinaturas. Gastar dinheiro no jogo não fornece nenhuma vantagem estatística para os jogadores antes ou durante uma partida, como argumentaremos nesta pesquisa. Isso denota que tais bens virtuais aqui analisados não desempenham um papel na melhoria do rendimento dos jogadores (FALCÃ0; MARQUES,
2017). Basicamente, na medida em que a habilidade e a competência de um jogador são muito mais valorizadas do que os bens virtuais que possui, para que um jogador seja bom em League ele não precisa gastar mais. Isso é distinto de um modelo pay-to-play (pagar para jogar), visto muitas vezes pela necessidade de investir dinheiro para vencer (pay-to-win) no intuito de obter uma melhor performance no jogo ${ }^{25}$.

Nesse sentido, embora $L o L$ condicione 0 jogador a jogar mais para gerar e destravar mais recursos para si, ele não o faz gastar mais financeiramente, como outras desenvolvedoras - como a Blizzard Entertainment - fazem em alguns de seus títulos (cf. FALCÃO; MARQUES, 2017). Certamente, essa característica distancia o $L o L$ de determinados jogos em que que gastar, muitas vezes, é visto como uma maneira realista de permanecer competitivo. Dito isto, tendo uma percepção inicial da natureza do jogo e dos princípios que fundamentam as diretrizes comerciais do MOBA, enquanto instâncias que impactam tanto sua jogabilidade quanto a obtenção de receitas, há algumas questões que merecem ser problematizadas. Sendo este um jogo em que a compra não é condicionada por uma recompensa baseada em vantagens

24 Massive Multiplayer Online Game (MMOG), ou Jogo Multijogador On-line em Massa, é um jogo de computador capaz de suportar conexões e partidas com milhares ou centenas de jogadores ao mesmo tempo. É, necessariamente, jogado na rede mundial de computadores, a internet.

25 Para mais informações acerca desses últimos dois modelos, uma consulta ao estudo de Thiago Falcão e Daniel Marques (2017) é apropriada. 
numéricas, o que leva um jogador a decidir por comprar? Por sua vez, o que torna o LoL um jogo on-line tão lucrativo?

0 sistema de classificação, existente em $L o L$ por meio do uso de bens de consumo virtuais, aciona um eixo para sua compreensão: os valores. Simmel (2005) argumenta que, se quisermos estabelecer uma compreensão teórica ou prática sobre 0 significado conceitual dos objetos, é necessário saber em que lugar eles são colocados na escala e ordem dos valores. 0 processo de classificação, quando ocorre em $L o L$, recorta um espaço que pode ser investigado a partir dos valores que recaem sobre ele. 0 que pretendemos, neste estudo, é analisar como esse sistema de classificação atua na manutenção, na articulação e no fomento de distinções na cultura do jogo, classificando diferentes jogadores por meio da posse de determinados bens. Isso nos permite, ainda, identificar os valores atribuídos a eles no sistema classificatório do jogo.

\section{0 papel das skins em League of Legends: práticas, motivações, economia dos bens virtuais e valores nas dinâmicas de consumo in-game}

\section{Em League, há uma oferta de conteúdos em constante renovação, o que dá uma sensação} de acesso e da completa trocabilidade dos bens. Segundo Everardo Rocha (2000), a troca é, antes de mais nada, simbólica como espaço para efetivação das relações sociais entre os sujeitos, com seus significados diversos que são postos em circulação. Esse fluxo constante e renovado de mercadorias torna a identificação do status ou posição hierárquica do portador de bens uma problemática complexa atual (FEATHERSTONE, 1995). Em LoL, há uma dinâmica similar ao que William Leiss (1983, p. 12) chama de "cenário de mercado de alta intensidade" ${ }^{26}$, pelo fato de existir grandes quantidades de bens, em constantes mudanças, que estão disponíveis para o consumo e venda aos jogadores, responsáveis por produzirem uma sensação de satisfação ou de insatisfação.

Nessa perspectiva, as mercadorias mais importantes são suscetíveis de se tornarem "bens posicionais" e funcionarem como tais. Conceito cunhado por Leiss (1983), "bens posicionais" são mercadorias nas quais o prestígio é decorrência da imposição de uma limitação de oferta, com frequência artificialmente criada para aumentar os valores dos bens como marcadores. Há diferentes níveis de valores e status, nesse tipo de bem, que variam conforme seu preço, dificuldade de obtenção e escassez. Draven, um dos interlocutores desta pesquisa, reforça a relevância que as mudanças propiciadas pelas skins trazem: "quanto mais muda, melhor; isso sem dúvida, por exemplo, às vezes, tem animações que têm pra uma skin que 
não têm pra outras, e aí isso dá uma diferença nela, quanto mais mudanças melhor".

Com a progressão e a evolução proporcionada a partir das mudanças nas capacidades técnicas incorporadas na produção de skins em $L o L$, e nas próprias atualizações pelas quais o jogo passa ao longo dos anos, o uso de diferentes níveis de efeitos, softwares e linguagens computacionais cria uma variedade de tipos de skins que garantem maior diferenciação e valores que mudam conforme a quantidade de alterações proporcionadas aos designs clássicos de campeões (figura 3 e 5$)^{27}$.

Figura 2: Texture update do design clássico do campeão Udyr, realizado em 2014, ao usar habilidades no jogo

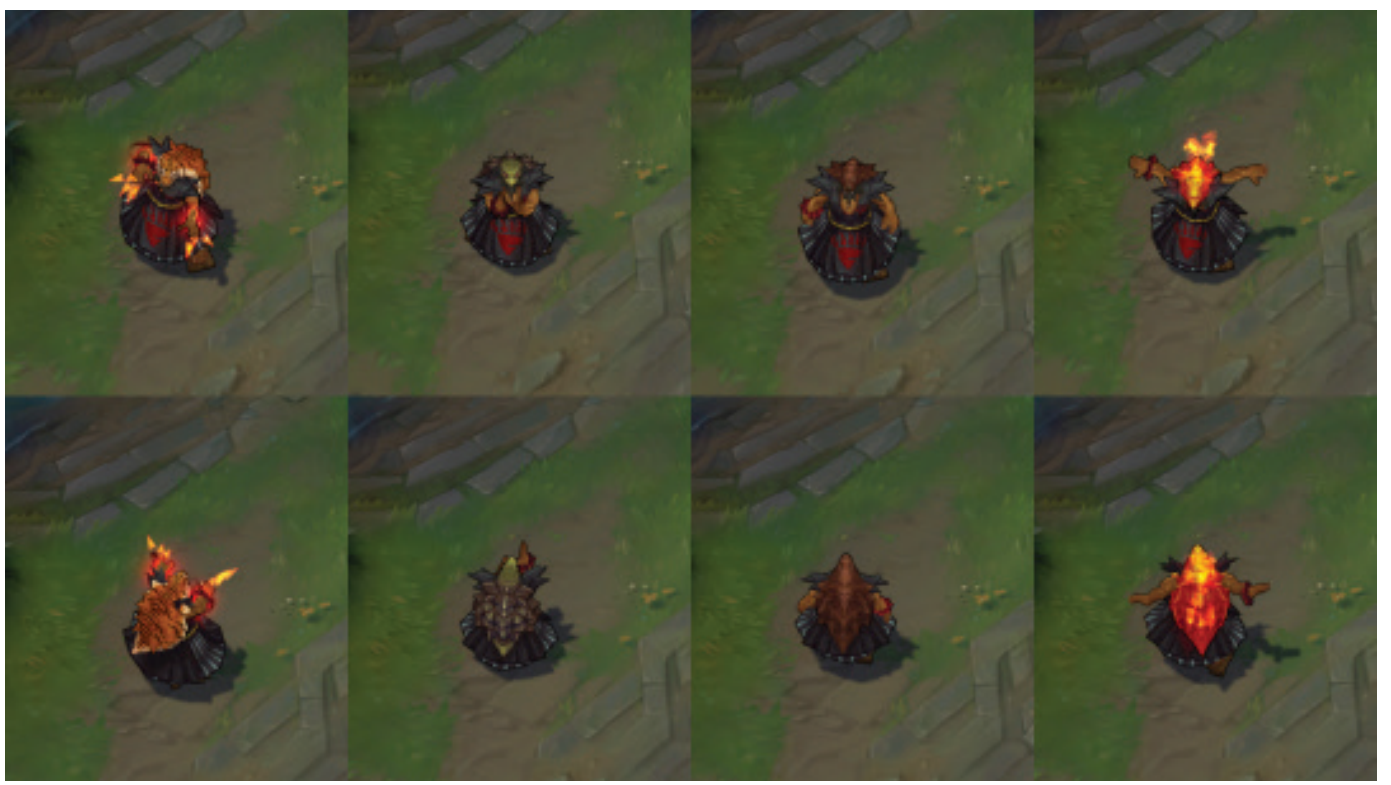

Fonte: Riot Games, League of Legends

Personagens lançados mais recentemente apresentam mudanças técnicas visíveis em relação aos primeiros, lançados ainda em $2009 \mathrm{e}$ em anos seguintes (figura 2), o que tem estimulado a empresa a, nos últimos anos, realizar revisões de seus personagens mais antigos e seus conjuntos de skins a partir de remakes, rework, relauch $\mathrm{e}$ texture update ${ }^{28}$.

Um remake trata-se de um novo visual/aparência para um personagem, enquanto que um rework é um retrabalho das habilidades, que também pode vir acompanhado de um remake. Um relauch ocorre quando um personagem recebe tanto um rework quanto um remake radical que provoca mudanças significativas na sua temática e narrativa. Por fim, texture update trata-se de atualizações nas texturas, entretanto, mantendo a modelagem original. 
Figura 3: Transformações no design da skin mítica ${ }^{29} \mathrm{Udyr}$ Guardião Espiritual, a partir do uso de habilidades no jogo

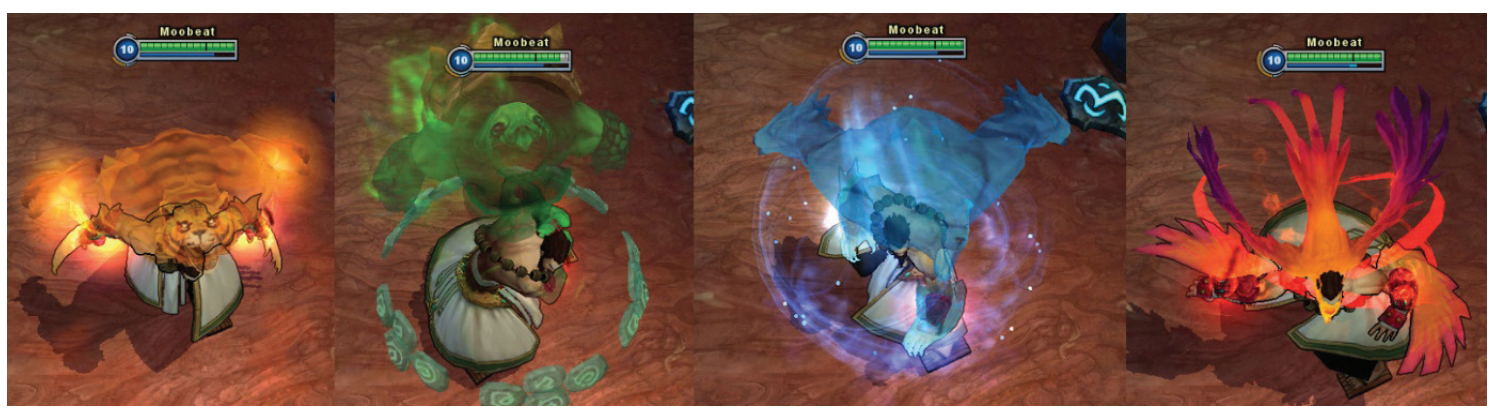

Fonte: Surrender at 20

Jinx e Talon, respectivamente, pontuam que as próprias skins acabam realizando diferentes modificações neste sentido, desde simples remakes até relauchs completos de personagens mais antigos (figura 3). Com efeito, são consumidos por jogadores conteúdos diferentes.

Uma coisa que é muito legal de perceber é, por exemplo, campeões mais antigos, quando eles recebem uma skin, eles já têm uma estética diferente. 0 campeão Udyr [figura 2] acho que é um bom exemplo, [pois] ele recebeu um novo trabalho, um upgrade [a partir de uma skin, figura 3], e aí isso é interessante, porque é mais um motivo para ti ter a skin, porque o campeão normal é "quadradão" e aí a skin já está à altura de personagens que foram lançados há um mês.

Às vezes o personagem nem é tão legal sem skin, vou dar um exemplo do Udyr, ele é um personagem que ele, sem skin, é um personagem muito, digamos assim, "mal-acabado", ele é um personagem antigo, por isso que ele tem esse visual "mal-acabado", pelo fato de vários personagens terem recebido rework, textura visual [texture update]. Então, como ele é muito antigo, ele foi um dos primeiros quarenta [a serem lançados com o jogo], ele é muito "feio" visualmente sem skin, então, você vê um cara com a skin do Udyr [Guardião Espiritual], ela é caríssima, é uma das mais caras do jogo, você vê os efeitos e você fala: "meu, eu quero ter aquilo, eu quero jogar de Udyr bonito" [risos].

0 que se pode apreender a partir desses relatos é que os bens virtuais também ganham prestígio por meio do valor de troca elevado que possuem, estabelecendo uma relação de "consumo conspícuo" (MARTIN, 2008; VEBLEN, 2007).

Segundo Everardo Rocha e Bruna Aucar (2014), é nesse sentido que provém do consumo a produção de um sistema de classificação, responsável por operar o distanciamento e/ou agrupamento dos sujeitos e coisas em uma estrutura de distinção.

Trata-se de um tipo de skin que pertence à categoria de skins ilimitadas, ou seja, disponíveis na loja por tempo indeterminado, e uma classe de skins chamada mítica ou ultimate. É a skin mais cara presente em LoL e possui 0 mais alto nível de alterações que esse tipo de bem pode alcançar. Uma skin mítica é caracterizada pela reconstrução completa de um personagem com a inserção de modelagem evoluída que muda em distintas formas ainda no jogo, conteúdos adicionais e a inclusão de bônus (como ícones de invocador exclusivos), novas texturas, animações, sons, visual, ilustração promocional e dublagem. 
Bens presentes em $L o L$ apresentam status por conta própria; entretanto, há distintos níveis desse status propagado por cada item, conforme sua classificação pelo sistema publicitário de League. 0 consumo é conspícuo em $L o L$ de múltiplas maneiras, sobretudo porque os itens mais desejáveis aos interlocutores são visíveis aos demais por meio dos seus personagens, sendo graficamente renderizados ${ }^{30}$, conforme destaca Lulu sobre a sensação de ter comprado a skin mítica Lux Elementarista (figura 5).

Eu me sinto "fodão" [risos], tipo, a da Lux [figura 4] eu sabia que eu ia feedar ${ }^{31}$ horrores, mas eu tava com a skin e era linda [figura 5]! Porque ela tem um monte de efeitos, todo mundo vai olhar e eu acho que eu causo esse medo, eu posso não saber nada da Lux, mas aí eu tô com a skin 0 outro time vai: "égua ${ }^{32}$, ele gastou 40 reais pra comprar essa skin!" É, assim, ou ele é rico demais ou ele lacra [arrasa] com a Lux, entendeu?

Duas dinâmicas podem ser percebidas a partir desse discurso de Lulu, igualmente evidente na fala anterior de Talon. A primeira trata-se da profundidade da experiência que uma skin mítica proporciona, os novos elementos ou funcionalidades que elas trazem a um determinado personagem. Lux Elementarista (figura 5), por exemplo, é dotada de uma multiplicidade de transformações com uma quantidade de conteúdo mutável durante o próprio jogo que impactam diretamente na experiência do jogador - assim como skin Udyr Guardião Espiritual.

Figura 4: Texture update do design clássico da personagem Lux, realizado em 2015

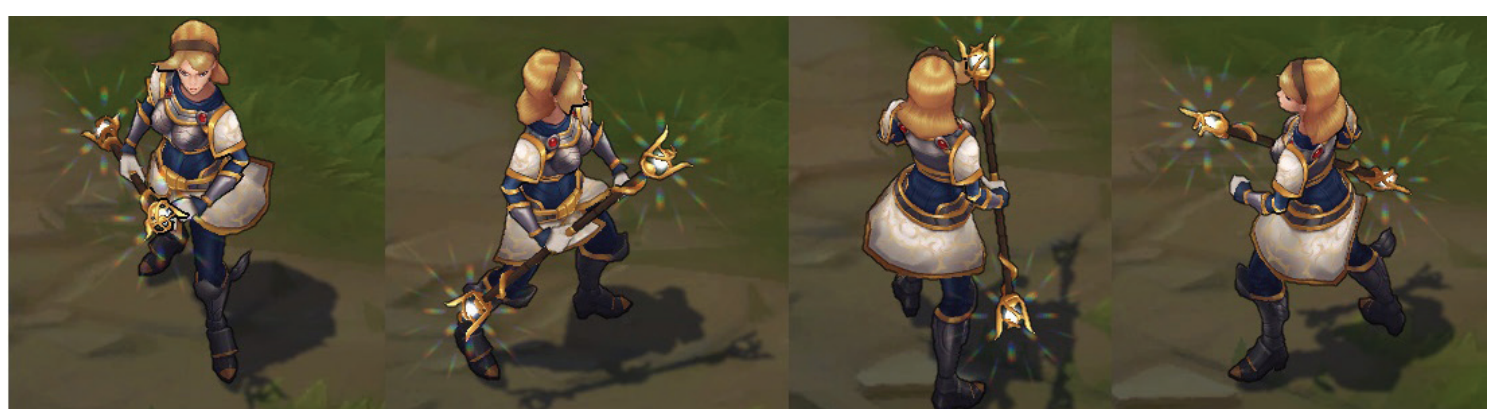

Fonte: Riot Games, League of Legends

30 Trata-se de uma atividade técnica que consiste na compilação para obter um produto final por meio de um processamento digital de uma sequência de imagens que foram, anteriormente, montadas em uma linha de vídeo.

31 Termo brasileiro, recorrente no ambiente de jogos digitais, que significa a morte repetitiva, e às vezes intencional, de um jogador para outro da equipe adversária. A expressão deriva do inglês feed, cujo significado literal seria "alimentar"

32 Regionalismo paraense, interjeição usada para demonstrar espanto. 
Figura 5: Distintas transformações no design da skin mítica Lux Elementarista, com modelagem evoluída que muda em distintas formas ainda no jogo

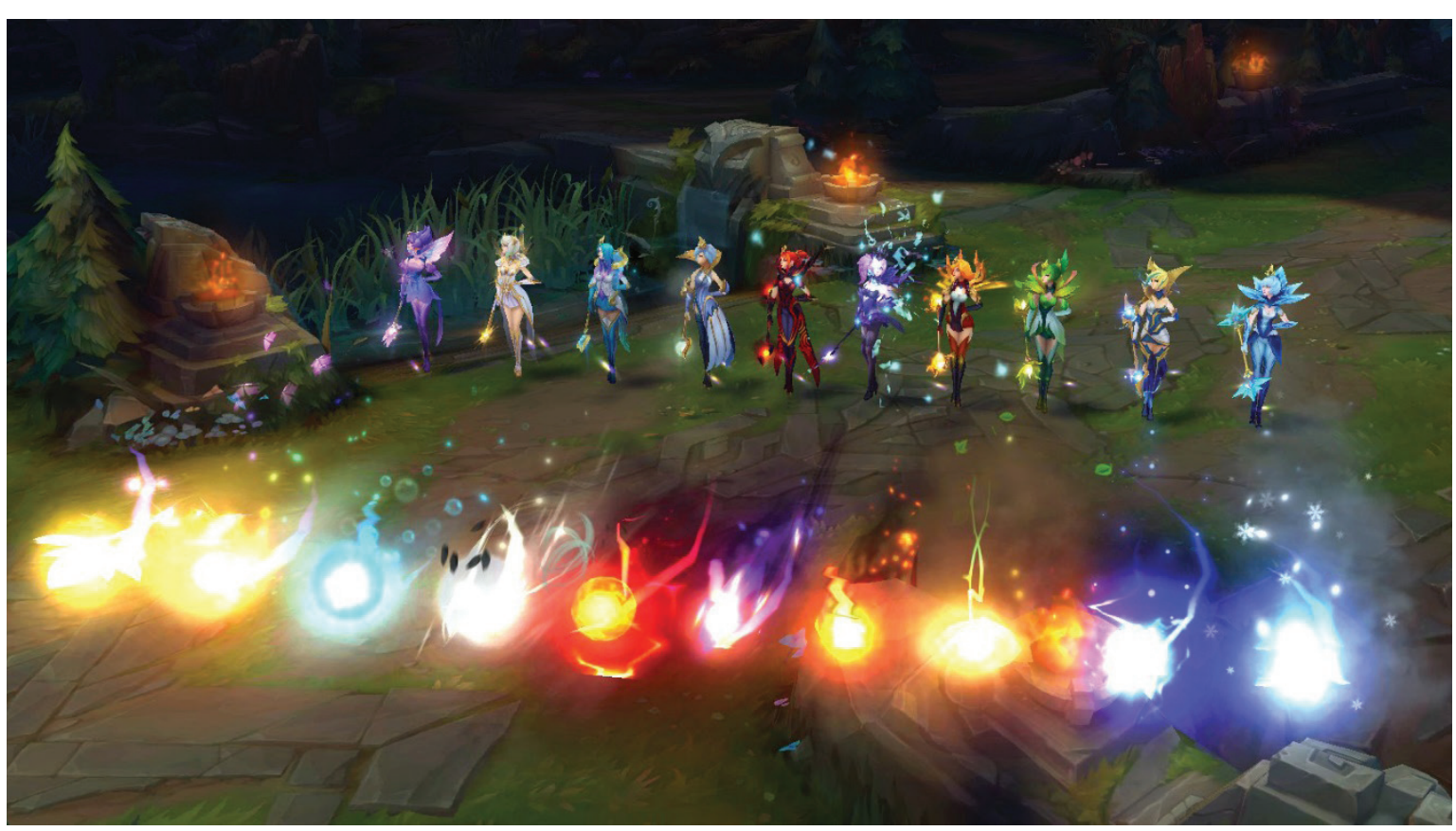

Fonte: Riot Games, League of Legends

Cada uma das skins míticas, especificamente,

implementa tanto uma profundidade de experiência

considerável quanto algo novo ao jogo. Por sua vez, um segundo aspecto advém de uma exposição da skin no jogo: Lulu não somente sinaliza para a posse de uma skin de percepção cara e de difícil acesso ${ }^{33}$, como também deseja exibir seu bem de modo que seja visível para os outros. Não basta apenas que ele o possua: seu consumo precisa ser conspícuo para revelar o status associado com seu produto. De maneira similar, Draven destaca:
Compro muita skin... todo mês eu coloco cinco mil de RP pra comprar skin, então, acho que é porque dá uma animada mais no jogo, você chegar na partida e o pessoal falar: "nossa, que skin maneira, que skin louca!" Alguém falar pra você dá até uma satisfação maior, dá até mais uma animada, você joga até com mais vontade, querer honrar a skin, honrar o campeão que você joga, basicamente é lindo.

De forma similar, skins limitadas ${ }^{34}$, não mais

colocadas à venda ou que têm uma carga afetiva intensa, tornam-se itens "sem preço" por simbolizarem relações pessoais marcantes ou evocarem memórias. Essa tendência das skins

33 Um sinal bastante visível de status, dado que deixa uma marca na própria paisagem do ambiente do game ao utilizar habilidades da personagem, além de criar um fundo dinâmico interativo no perfil do jogador em LoL.

34 Trata-se de skins consideradas mais raras porque foram disponibilizadas na loja temporariamente durante a realização de eventos especiais, porém, foram removidas logo que o evento findou. 
de se tornarem objetos de valorização perpassa a possibilidade de significados que serão construídos e desdobrados junto aos sujeitos, por meio das ações de ordem simbólica - e da ordem de valor - do jogar o jogo. Mike Featherstone (1995) argumenta que um objeto que não esteja disponível à venda e que não tenha um preço específico pode se tornar ainda mais caro, raro e com alto status, sendo, por conseguinte, bastante desejado.

Para Georg Simmel (2005), o valor torna-se correlato à demanda, "nesta série, a qualidade fundamental não é a uniformidade, mas a diferença" (SIMMEL, 2005, p. 56) ${ }^{35}$. E reforça:

Nós desejamos objetos somente se eles não nos forem imediatamente entregues para 0 nosso uso e prazer, isto é, na medida em que eles resistem ao nosso desejo [...]. Os objetos não são difíceis de se adquirirem porque são valiosos, mas chamamos de valiosos a esses objetos que resistem ao nosso desejo de possuí-los. Uma vez que o desejo encontra resistência e frustração, os objetos ganham um significado que nunca teria sido atribuído a eles por uma vontade não controlada $^{36}$ (SIMMEL, 2005, p. 63-64).

A perspectiva levantada por Simmel (2005) realça a ideia de que objetos valiosos apresentam-se aos sujeitos rodeados por uma espécie de efeito de resistência, e esta é responsável por ser a fonte do seu valor. Nesse sentido, o consumo em $L o L$ se dá também em busca da distinção, que a "personalização era diretamente relacionada com a diferenciação social, o 'ser diferente' diante da rede. Quando mais original, melhor" (RECUER0, 2009, on-line). Esse argumento, proposto por Raquel Recuero (2009), aparece como fundamental na fala de Draven:

É muito melhor uma coisa diferente, uma coisa incomum, do que uma coisa comum. Eu, pelo menos, penso assim, penso que uma coisa incomum é muito melhor do que a comum, porque a comum você pode achar em qualquer lugar; agora, 0 incomum a gente acha em lugares um pouco mais de difícil acesso. 0 incomum é melhor.

A fala do interlocutor ajuda a compreender como o consumo manifesta-se como palco da diferença, o quanto "ele é um dos grandes inventores das classificações sociais que regulam as visões de mundo" (ROCHA, 2000, p. 19 , grifo do autor). Desta forma, no momento em que esses bens perdem a "raridade", centrando-se em uma maior disponibilidade social, seu valor é diminuído (baixando, inclusive, o seu preço), tornando-se, então, um bem de mais fácil acesso a alguns jogadores no MOBA (FEATHERSTONE, 1995).

Leiss (1983) salienta, similarmente, que, no momento em que "bens de posição" tornam-se

Tradução do original: "in this series, the fundamental quality is not uniformity but difference".

Tradução do original: "We desire objects only if they are not immediately given to us for our use and enjoyment; that is, to the extent that they resist our desire [...]. Objects are not difficult to acquire because they are valuable, but we call those objects valuable that resist our desire to possess them. Since the desire encounters resistance and frustration, the objects gain a significance that would never have been attributed to them by an unchecked will". 
amplamente disponíveis, sendo propagados a todos ou à maioria dos sujeitos, suas vantagens individuais são largamente anuladas. Tal aumento do consumo e da demanda por esses bens provoca esse processo, a exemplo de skins distribuídas gratuitamente para uma ampla maioria de jogadores.

Como exemplo, Draven, Jinx e Talon argumentam que uma skin perde 0 valor quando todos a possuem. Isso significa, portanto, que a ordem dos valores dos bens virtuais é mutável a todo instante a partir das interações que ela sofre nos ambientes. A satisfação e o desejo passam a depender, portanto, do consumo e da posse de bens que são sancionados e legitimados, $\log _{0}$, limitados ou escassos (FEATHERSTONE, 1995; SIMMEL, 2005). Braum, outro interlocutor desta pesquisa, por sua vez, declarou-nos: "eu sou do contra e egoísta, não gosto de skins free [grátis], porque quero ser exclusivo". Essa afirmação caminha em direção ao argumento de Leiss (1983), segundo o qual as mercadorias que possuem maior valor financeiro, por critérios como a escassez de oferta e 0 alto preço, costumam vincular-se ao status social dos indivíduos que as detêm. Tratam-se de "bens posicionais" - característica também inerente aos bens virtuais em $L o L$.
Nesse sentido, as falas dos interlocutores ressaltam que 0 valor experimentado pelos jogadores se relaciona com sentimentos e percepções de que possuem conteúdos significativos. Afinal, conforme destaca Simmel (2006, p. 45-46), "para a ação no âmbito das relações do indivíduo, a diferença perante outros indivíduos é muito mais importante que a semelhança entre eles". Portanto, as argumentações dos interlocutores também demonstram que o consumo de objetos atualmente é, conforme sustenta Ian Woodward (2007), uma esfera para estabelecimento de posições e diferenciações sociais. Para 0 autor, a sociedade contemporânea de consumo fundamenta-se na "materialização da distinção", ou seja, "a codificação da diferença cultural e de status nos próprios objetos" (WOODWARD, 2007, p. 113, grifo do autor) ${ }^{37}$.

Erving Goffman (1951), em trabalho sobre os símbolos de status de classe, argumenta que objetos possuem funções categóricas que servem para distinguir o lugar social das pessoas ao usarem determinados símbolos. Como exemplo, vemos, em League, que cada tipo de skin tem particularidades conforme variam seus valores para aquisição. Tipos de ${\text { skins } \text { legado }^{38} \text {, ultimate }}^{39}$, míticas ou limitadas circunscrevem símbolos de

37 Tradução do original: "materialisation of distinction: the coding of cultural and status difference in objects themselves".

38 Trata-se de itens considerados relativamente raros por conta da sua disponibilidade limitada para compra na loja, geralmente acessíveis em datas e épocas específicas no MOBA, durante o resto do ano permanecem no que a empresa chama de "cofre das skins legado". Trata-se de itens sazonais.

Trata-se de um tipo de skin que pertence à categoria de skins ilimitadas, ou seja, disponíveis na loja por tempo indeterminado, e uma classe de skins chamada de ultimate ou lendária. É a segunda skin mais cara presente em LoL. Esse tipo de skin é caracterizado pela modificação completa do visual e do aspecto de um personagem com a inserção de novas modelagens, texturas, ilustração promocional, além de animações, dublagem, sons e visual completamente inéditos. 
status que sinalizam para a riqueza de jogadores no jogo. É nessa perspectiva que, seguindo o pensamento de Featherstone (1995), existe um duplo aspecto simbólico de bens virtuais em jogos digitais como LoL: (i) de um lado há uma carga de simbolismo presente no design e no imaginário introduzidos nos processos de marketing e de produção de mercadorias como as skins; (ii) de um outro, há uma diversidade de associações simbólicas utilizadas e renegociadas para destacar diferenças de estilo de vida, delimitando as relações sociais nos jogos.

Skins diferentes apresentam modos de funcionamentos distintos e interferem de maneiras específicas na natureza das relações sociais no MOBA. Ao passo que esse tipo de bem proporciona determinadas "vantagens" no jogo, há uma série de cobranças e expectativas por parte de outros jogadores, conforme demonstramos em estudo anterior (MACED0; VIEIRA, 2017a). Logo, os tipos de skins constituem-se em um conjunto de representações utilizadas no ato de classificar a maestria, a perícia de adversários ou aliados com campeões diversos (MACEDO; VIEIRA, 2017a), conforme assinala Draven, em concordância com Jinx, Lulu e Talon.

Olha, se meu time inteiro tá cada um com uma skin, eu vou ficar muito feliz cara [risos]! Porque a primeira impressão conta muito. Você pensa: "bom, o cara tem uma skin pra esse campeão, então provavelmente ele deve saber jogar com ele" [...], então, às vezes, pode ser bom, você se sente bem no começo até você ver 0 cara jogando [...].
A fala de Draven coloca em evidência que a compreensão de bens de consumo no jogo ocorre por livre associação, cujo objetivo parecenos produzir um efeito expressivo de perícia, habilidade e competência nas dinâmicas de personagens e do MOBA; um desejo de ser reconhecido impele a emoção para o uso de skins no jogo (MACED0; VIEIRA, 2017a, 2017b). Essa questão, apesar de evidente dentro dos motivos que os interlocutores alegaram para adquirir tais bens, é contraposta pela possibilidade da compra de skins pela satisfação estética, pelos prazeres sensíveis e hedônicos que elas possam despertar, como argumentado por Jinx, como pretexto principal para adquirir skins: "eu compro porque eu achei legal. As minhas skins eu comprava porque achava a skin bonita".

Em outra perspectiva, Draven também reforça a possibilidade para 0 consumo desses itens ao falar que, apesar da expectativa, um jogador pode simplesmente comprar uma skin porque se encontrava na promoção, independentemente do status que ela poderia carregar no jogo. Em relação à promoção, essa não pareceu ser uma preocupação grande da maioria dos nossos interlocutores quando pretendem comprar skins em LoL. Há uma exceção entre os interlocutores: Lulu foi 0 único a afirmar que comprava quase todas as suas skins exclusivamente por promoções, com poucas exceções a esta regra.

Vêm promoções de skins, e aí eu sempre vejo lá o que que tem [na loja do jogo], mas sempre pensando na promoção, fazer com que meu 
dinheiro seja investido bem [...]. Porque, às vezes, a skin é bonita, só o design, eu gosto muito, mas eu gostaria de comprar as mais caras, só que né? [...].

A maneira como os jogadores consomem bens em League também está associada aos atributos relativos aos próprios produtos (LEHDONVIRTA, 2009). Tais objetos são marcados pela completa ausência de atributos baseados em valor de $\mathrm{uso}^{40}$, como performance (vantagens numéricas para os personagens) ou funcionalidade (novas habilidades e opções para avanço no jogo) (LEHDONVIRTA, 2009), uma vez que a compra de uma skin em League não altera em nada os atributos ou configurações dos personagens no jogo (MACED0; AMARAL, 2015).

A partir do trabalho de Juliana Abonizio (2015) a respeito das coleções de fãs, podemos pensar nas skins como objetos excluídos do estado de mercadoria, já que ganham valores e são subordinadas a zelos especiais. Assim, esses objetos em jogo possuem valor de troca embora pouco efetivo - sem terem valor de uso. No entanto, esse valor de troca não pode ser considerado formal, uma vez que o sistema de LoL não torna possível a criação de um mercado/ economia entre os próprios jogadores para venda de skins ou qualquer outro tipo de bem virtual, logo, sendo a compra de itens fixa ao usuário pela loja oficial do jogo.

Uma vez ausente 0 valor de uso de bens virtuais do tipo skin em League, será a função simbólica deles responsável por determinar os papéis dessas mercadorias dentro das dinâmicas do jogo, os valores cambiais e o status a partir dos quais eles serão comercializados. Portanto, a ideia de valores simbólicos associados às skins em $L o L$ pode ser compreendida em relação tanto com 0 que elas significam para os sujeitos (subjetivo e individual), quanto o que representam para a comunidade em geral (coletivo e pertencimento). Obviamente, essa dinâmica não é exclusiva do consumo de bens virtuais em League, como indicam as pesquisas de Vili Lehdonvirta (2009) e Vili Lehdonvirta, Terhi-Anna Wilska e Mikael Johnson (2009), sendo necessário reconhecer que tais dinâmicas de consumo são recorrentes de determinadas tendências advindas pela adoção de certos modelos de negócios em jogos digitais. Como exemplo, a pesquisa de campo demonstrou que os consumidores de $L o L$ são, principalmente, motivados ao ato de compra pela busca de status e posse de raridades caras.

A dinâmica apresentada pelos jogadores mostra que o conhecimento do valor social e cultural

Segundo argumenta Lehdonvirta (2009), os atributos considerados utilitários ou funcionais dos bens são aqueles que propiciam que eles possam ser usados como utensílios para realizar algum escopo maior, comumente um propósito material tangível, que é percebido como relacionado a alguma necessidade humana fundamental. Embora essa seja uma razão básica para considerar bens valorizados, não se trata do único motivo para a criação de valores em produtos nas sociedades de consumo contemporâneas (SIMMEL, 2005; LEHDONVIRTA, 2009). 
dos bens em $L o L$, o significado de usá-los em determinados contextos, torna-se primordial para a interpretação das relações no jogo. No papel de marcador, Lehdonvirta, Wilska e Johnson (2009) defendem que as características estéticas e funcionais (embora esse último não exista em $L o L$ ) de determinados objetos podem deixar de serem relevantes, uma vez que atributos extrínsecos - em especial no que tange à raridade, exclusividade e associação com sujeitos ou grupos específicos (neste caso, a comunidade de $L o L$ ou os jogadores de determinados personagens) - tornam-se as forças motrizes das escolhas de consumo. Na seção seguinte, o que se segue é um breve resumo das descobertas descritas acima, cujo objetivo é de estruturar e articular os principais resultados obtidos nesta pesquisa.

\section{Compêndio das constatações: uma síntese das contribuições da pesquisa}

Podemos compreender os bens de consumo virtuais, presentes em $L o L$, como sendo articulados a partir dos seguintes critérios: escassez, custo, relevância e qualidade, sendo todos relacionados à categoria "decorativo", na qual os três primeiros fatores são relacionados às subcategorias sociais, e 0 último à subdivisão hedônica. 0 primeiro concerne ao nível de disponibilidade dos bens; portanto, há uma relação inversamente proporcional entre 0 aumento da disponibilidade e sua consequente valorização, embora seja preciso um limite entre a distância do sujeito e as skins para que não seja prejudicial ao desejo $0^{41}$. Portanto, a raridade é, possivelmente, um dos atributos dos bens mais socialmente orientados (LEHDONVIRTA, 2009), uma vez que seu valor se encontra fortemente associado à capacidade de distinguir grupos que possuem daqueles que não possuem.

Nesse sentido, um bem virtual, para que seja atrativo aos jogadores, necessita de um equilíbrio entre escassez e custo. Este, por sua vez, coloca em questão o fato de que nem todos os sujeitos estão dispostos a pagar muito por bens virtuais; assim sendo, tal custo necessita de uma simetria de benefício proporcionado (permanente ou casual). No caso de $L o L$, embora não haja um valor de uso ou um valor de troca formal, o valor simbólico apresentado é articulado a partir tanto dos atrativos sociais quanto dos estéticos. Portanto, "os bens virtuais são mais adequados para criar e manter distinções e vínculos sociais por causa de sua rivalidade e escassez" (LEHDONVIRTA, 2009, p. 111) ${ }^{42}$. Dentro das

41 Para Simmel (2005), há um limite inferior e superior para a distância entre sujeito e objeto, responsável por estabelecer o valor. 0 autor complementa: "a fórmula de que a quantidade de valor é igual ao grau de resistência à aquisição de objetos, em relação às oportunidades naturais, produtivas e sociais, não é correta” (SIMMEL, 2005, p. 69, tradução nossa), na medida em que a distância em excesso leva a uma problemática na criação do desejo.

42 Tradução do original: "virtual goods are more suited to creating and maintaining social distinctions and bonds because of their built-in rivalry and scarcity". 
diferentes motivações que os jogadores têm para a compra de bens virtuais do tipo skin, elencamos os atributos identificados no quadro
2 , enquanto reflexos da pesquisa no intuito

de fazer uma leitura mais didática sobre os resultados do estudo.

Quadro 2: Identificando diferentes percepções dos sujeitos para a compra de bens virtuais do tipo skin

\begin{tabular}{|c|c|c|}
\hline $\begin{array}{l}\text { Categoria dos bens } \\
\text { virtuais do tipo skin }\end{array}$ & Subcategorias & $\begin{array}{l}\text { Atributos atrativos dos bens virtuais do tipo } \\
\text { skin atuando como vetores de decisões de compra }\end{array}$ \\
\hline \multirow{2}{*}{$\begin{array}{c}\text { Funcional } \\
\text { (valor de uso) }\end{array}$} & Performances & $\star \star \star *$ \\
\hline & Funcionalidades & $\star \star \star ~$ \\
\hline \multirow{2}{*}{$\begin{array}{c}\text { Decorativo } \\
\text { (valor simbólico) }\end{array}$} & Sociais & $\begin{array}{c}\text { Relevância: poder, exclusividade pelo uso de skins (proveniência difícil), escassez } \\
\text { de acesso, custo, avanço na hierarquia de status diante dos demais, confiança } \\
\text { dos aliados (favorece o trabalho em equipe e a motivação para uma organização } \\
\text { eficaz, a princípio), "vantagens" em configurações competitivas (imposição de } \\
\text { medo nos inimigos a partir do uso da skin) e demostrar um nível elevado de } \\
\text { perícia com determinado personagem. }\end{array}$ \\
\hline & Hedonistas & $\begin{array}{l}\text { Qualidade: aparência visual (estética) da skin, experiência estética (novas experiências } \\
\text { com um personagem, mais opções sobre qual conteúdo usar), customização do } \\
\text { personagem (obtenção de um conjunto de ativos que correspondem, em certo } \\
\text { sentido, às preferências do jogador), relação emocional individual ou técnica com os } \\
\text { personagens, desejos/sonhos do próprio jogador, referências culturais - skins sazonais } \\
\text { nacionais, baseadas em eventos ou festividades mundiais - e autoexpressão (permite } \\
\text { a expressão dos jogadores por meio das escolhas de compra). }\end{array}$ \\
\hline
\end{tabular}

Fonte: Elaborado pelos autores

0 exame de bens virtuais do tipo skin, portanto, mostra-nos que 0 valor de uso não é uma particularidade necessária para a aquisição, e que 0 valor simbólico - a experiência que propiciam imbuída de prazeres emocionais hedônicos e atributos sociais - também pode ser uma das forças motrizes por trás do consumo em jogos digitais como LoL. Em alguns destes, como é em $L o L$, os valores simbólicos (características hedônicas e/ou sociais) são acionados para o primeiro plano no processo do consumo das dinâmicas que permeiam os usos de bens em diferentes situações e para diversos fins no ambiente de League ao serem exibidos em partidas.

Os resultados do trabalho de campo realizado indicaram que a principal busca dos jogadores 
de $L o L$, acerca do consumo dos bens skin, relaciona-se com 0 anseio por diferenciações em relação aos demais jogadores do jogo. Neste sentido, a categoria desses bens enquanto itens "decorativos" sobressai em relação à categoria "funcional", haja vista que esta não existe enquanto parte dos atributos das mercadorias postas à venda. Embora os atributos funcionais, hedônicos e sociais possam coexistir simultaneamente em um mesmo bem, em League a primeira dessas categorias é ausente.

A economia do consumo de bens virtuais do tipo skin em League aponta duas perspectivas possíveis. Podemos interpretar essa prática pela relação existente entre a satisfação que esses bens proporcionam e 0 seu acesso social de visibilidade, logo da exibição, e da conservação das diferenças em situações de inflação no ambiente do jogo. Os jogadores utilizam tais conteúdos com o objetivo de formar vínculos ou estabelecer diferenciações sociais. A satisfação passa a depender, portanto, do consumo e da posse de bens que são sancionados e legitimados, logo, limitados ou escassos (FEATHERSTONE, 1995). Em segundo lugar, há uma dinâmica que envolve os prazeres emocionais do consumo, sonhos e desejos promovidos no imaginário individual que produz distintos tipos de estímulos físicos, satisfações emocionais e prazeres estéticos derivados da experiência do consumo.

Nessa perspectiva, o consumo pode ser visto como um processo hedonista pela busca de prazer, em que a aparência visual das skins, além de darem origem a valores sociais, também podem ser vistas como relacionadas aos prazeres individualistas e hedonistas (FEATHERSTONE, 1995). Assim, bens virtuais do tipo skin são capazes de fornecerem respostas hedônicas e emocionais a partir das suas aparências visuais, mas igualmente por meio das ficções de fundo ou narrativas associadas a eles $^{43}$ (LEHDONVIRTA, 2009; MACEDO; AMARAL, 2015; MACED0; VIEIRA, 2017b).

\section{Considerações finais}

0 percurso argumentativo central neste artigo pretendeu refletir sobre as dinâmicas das categorias social e hedônica dentro do consumo de skins no âmbito do jogo on-line League of Legends, enquanto resultados latentes de uma análise empírica conduzida para produzir uma compreensão detalhada sobre o consumo de bens virtuais no MOBA. Neste estudo, analisamos algumas das motivações que influenciam e orientam os jogadores a comprarem bens virtuais do tipo skin em LoL. Os resultados desta pesquisa que compõe o jogo, escapa ao escopo do objeto desta pesquisa. Embora parte dessa esfera analítica figure em trabalhos anteriores (MACEDO; AMARAL, 2015; MACEDO; VIEIRA, 2017b), demonstra uma lacuna na agenda de pesquisa sobre 0 consumo de bens virtuais em jogos digitais, ao passo que indica uma direção e orientação futura a ser perseguida em pesquisas de estudiosos que queiram adentrar nos estudos sobre o consumo em jogos digitais. 
levaram a uma proposta de classificação dos atributos desses bens em duas categorias: hedônicos e sociais.

Desta forma, de um lado observamos as dinâmicas desse "consumo virtual" nos modos de satisfação de aspectos emocionais individuais e, por outro, dos marcadores sociais para traçar distinções entre quem "tem" e "não tem", o que constrói uma comunicação do status social para outros membros da comunidade de $L o L$. Diretamente, a pesquisa apontou para a combinação de duas motivações, com maior destaque: relevância (atributo social) e/ou qualidade (atributo hedônico). No entanto, os atributos hedônicos são difíceis de distinguir empiricamente dos atributos sociais, embora sejam conceitualmente diferentes (LEHDONVIRTA, 2009), os quais se referem a atributos (sociais) que tornam itens virtuais relevantes para comunicar e criar distinções sociais.

Todavia, não se pode afirmar que inexiste senso de necessidade agregado ao consumo dentro de LoL. Uma vez que essa impressão de necessidade é constituída não em concepções tradicionais de necessidades físicas e materiais de valores de uso, mas em significados simbólicos em torno do potencial para expressar poder, individualidade, status, pertença e hierarquia devido à natureza gráfica de League e pela consequente visibilidade dos bens no ambiente do jogo, esses motivos associados às compras são explorados em termos dos papeis que podem assumir para os jogadores.
Longe de esgotarmos o tema, compreender esse cenário é um desafio a ser seguido na compreensão das práticas, da narratividade e dos estudos acerca do consumo de bens virtuais em jogos digitais, empreendendo tanto oportunidades emergentes quanto multiplicando os desafios para os estudiosos que realizam ou pretendem efetivar pesquisas nesta área. Pensar criticamente nos enredos e nuances que incorporam esse mundo contemporâneo reivindica a criação de uma agenda de pesquisa que envolva as diversas questões que perpassam a seara da discussão no campo das interações dos jogos digitais.

Os apontamentos aqui expostos tratam, portanto, de evidenciar algumas reflexões exploratórias que podem nortear a discussão de uma economia dos bens virtuais em jogos on-line, o que sugere e demanda, por sua vez, projetos futuros que possam explorar essa argumentação em diferentes tipos de jogos. Tais questionamentos, todavia, podem contribuir para a criação de uma agenda de tensão e debate que enseje pensar as complexas relações existentes entre consumo, hedonismo e aspectos sociais, enquanto três eixos-chave de articulação em interface com o universo dos jogos on-line e o campo dos Game Studies.

\section{Referências bibliográficas}

AARSETH, Espen. 0 Jogo da Investigação: abordagens metodológicas à análise de jogos. Caleidoscópio: Revista de Comunicação e Cultura, Lisboa, n. 4, p. 9-23, 2003.

APPERLEY, Thomas; JAYEMANE, Darshana. Game Studies' Material Turn. Westminister Papers in 
Communication and Culture, London, v. 9, n. 1, p. 5-25, 2012.

ABONIZIO, Juliana. Do fundo do baú: as coleções dos fãs de Raul Seixas. Comunicação, Mídia e Consumo, São Paulo, v. 12, n. 33, p. 57-73, jan./abr. 2015.

CAILLOIS, Roger. 0s jogos e os homens: a máscara e a vertigem. Lisboa: Cotovia, 1990.

DOUGLAS, Mary; ISHERWO0D, Baron. 0 mundo dos bens: por uma antropologia do consumo. 2. ed. Rio de Janeiro: Editora UFRJ, 2013.

FALCÃO, Thiago. Não-humanos em Jogo. Agência e Prescrição em World of Warcraft. Tese de Doutorado apresentada à Universidade Federal da Bahia. Salvador, 2014.

; MARQUES, Daniel. Pagando para vencer: cultura, agência e bens virtuais em video games. Contracampo, Niterói, v. 36, n. 2, p. 133-156, ago./out. 2017.

FEATHERSTONE, Mike. Cultura de Consumo e PósModernismo. São Paulo: Nobel, 1995.

GOFFMAN, Erving. Symbols of Class Status. The

British Journal of Sociology, London, v. 2, n. 4, p. 294-304, 1951.

HAMARI, Juho; LEHDONVIRTA, Vili. Game Design as Marketing: How Game Mechanics Create Demand for Virtual Goods. International Journal of Business Science \& Applied Management, United Kingdom, v. 5, n. 1, p. 14-29, 2010.

LEHDONVIRTA, Vili. Virtual Item Sales as a Revenue Model: Identifying Attributes That Drive Purchase Decisions. Electronic Commerce Research, New York v. 9 , n. 1-2, p. $97-113$, jun. 2009.

; WILSKA, Terhi-Anna; JOHNSON, Mikael.

Virtual Consumerism: Case Habbo Hotel. Information, Communication \& Society, London and New York, v. 12, n. 7, p. 1059-1079, set. 2009.
LEISS, William. The icons of the marketplace. Theory, Culture \& Society, London, v. 1, n. 3, p. 10-21, 1983.

MACED0, Tarcízio; AMARAL, Otacílio. Dos rios à tela de cristal líquido: o retorno do mito e a arquitetura da cultura convergente em League of Legends. Revista Fronteiras: estudos midiáticos, São Leopoldo, v. 17, n. 2, p. 231-247, maio/ago. 2015.

; VIEIRA, Manuela. Mais do que apenas dedos rápidos: narrativas e experiências de performances em League of Legends. Lumina, Juiz de Fora, v. 11, n. 1, p. 1-20, jan./abr. 2017a.

Muito além dos pixels: experiências de consumo e cultura material em League of Legends. Comunicação, Mídia e Consumo, São Paulo, v. 14, n. 41, p. 146-170, set./dez. 2017b.

MARTIN, Jennifer. Consuming Code: Use-Value, Exchange-Value, and the Role of Virtual Goods in Second Life. Journal of Virtual Worlds Research, Austin, v. 1, n. 2, p. 1-21, 2008.

REBS, Rebeca. Bens virtuais em social games. Revista Intercom, São Paulo, v. 35, n. 2, p. 205-224, 2012.

RECUER0, Raquel. Sobre bens virtuais. 2010. Disponível em: < https://goo.gl/DBR3aq> . Acesso em: 15 jun. 2017.

ROCHA, Everardo. Totem e consumo: um estudo antropológico de anúncios publicitários. Alceu, Rio de Janeiro. v. 1, n. 1, p. 18-37, jul./dez. 2000.

; AUCAR, Bruna. Cultura material e convergência de mídia: um estudo sobre a construção da subjetividade contemporânea. In: ROCHA, E.; PEREIRA, C.; BARROS, C. (Orgs.). Cultura e experiência midiática. Rio de Janeiro: Mauad X e Editora PUC-Rio, 2014.

SALEN, Katie; ZIMMERMAN, Eric. Rules of Play: Game Design Fundamentals. Cambridge/MA: MIT Press, 2004.

SIMMEL, Georg. Fashion. American Journal of Sociology, Chicago, v. 62, n. 6, p. 541-548, 1904/1957. 
Questões fundamentais da sociologia. Rio de Janeiro: Zahar, 2006.

The Philosophy of Money. 3 ed. London and New York: Routledge, 2005.

TAYLOR, T. L. Power gamers just want to have fun? Instrumental play in a MMOG. In: COPIER, Marinka; RAESSENS, Joost. (Eds.). Level Up Games Conference Proceedings. Utrecht: Universiteit Utrecht, 2003.

VEBLEN, Thorstein. The theory of the leisure class. New York: Oxford University Press, 2007.

WOODWARD, Ian. Understanding Material Culture. London: Sage, 2007. 


\section{Dynamics of virtual goods} consumption: practices and values in the League of Legends universe

\section{Abstract}

This article seeks to understand the consumption of virtual goods in the everyday practices of players of the online game League of Legends $(\mathrm{LoL})$ to reflect on the particular social constitution of consumers of this online game. The object of study focused on the skins available in LoL, which were specifically observed in the relations established with the players and their motivations of acquisition and interpretation of these goods in the game environment. The theoretical-analytical framework starts from the orientation of the anthropological approach to consumption. As an empirical clipping, the discussion will be evidenced through a research with ethnographic premises with a group of LoL consumers from the cities of Belém (PA), Diadema (SP) and 0sasco (SP). The reflections indicate that the main motivations for the consumption of these commodities in League are based on the essential acting of the symbolic values to the detriment of the values of use and exchange.

\section{Keywords}

Consumption. Virtual goods. Digital game.

\section{Dinámicas del consumo de bienes} virtuales: prácticas y valores en el universo de League of Legends

\section{Resumen}

Este artículo busca comprender el consumo de bienes virtuales en las prácticas cotidianas de jugadores del juego on-line League of Legends $(L o L)$ para reflexionar sobre la propia constitución social de los consumidores de este juego on-line. El objeto de estudio se centró en las skins disponibles en $L o L$, las cuales fueron específicamente observadas en las relaciones establecidas con los jugadores y sus motivaciones de adquisición e interpretación de estos bienes en el ambiente del juego. El marco teórico-analítico parte de la orientación del enfoque antropológico del consumo. Como recorte empírico, la discusión será evidenciada por medio de una investigación con premisas etnográficas con un grupo de consumidores de $L o L$ de las ciudades de Belém (PA), Diadema (SP) y 0sasco (SP). Las reflexiones indican que las motivaciones principales para el consumo de estas mercancías en League se basan en la actuación esencial de los valores simbólicos en detrimento de los valores de uso y de cambio.

\section{Palabras-clave}

Consumo. Bienes virtuales. Juego digital. 


\section{Expediente}

A revista E-Compós é a publicação científica em formato eletrônico da Associação Nacional dos Programas de Pós-Graduação em Comunicação (Compós). Lançada em 2004, tem como principal finalidade difundir a produção acadêmica de pesquisadores da área de Comunicação, inseridos em instituições do Brasil e do exterior.

\section{E-COMPÓS I www.e-compos.org.br I E-ISSN 1808-2599}

Revista da Associação Nacional dos Programas de Pós-Graduação em Comunicação. Brasília, v.21, n.1, jan./abr. 2018. A identificação das edições, a partir de 2008, passa a ser volume anual com três números. Indexada por Latindex I www.latindex.unam.mx

\section{CONSELHO EDITORIAL}

Ada Cristina Machado Silveira, Universidade Federal de Santa Maria, Brasil Alda Cristina Silva da Costa, Universidade Federal do Pará, Brasil Alfredo Luiz Paes de Oliveira Suppia, Universidade Estadual de Campinas, Brasil Ana Regina Barros Rego Leal, Universidade Federal do Piauí, Brasil Ana Carolina Rocha Pessôa Temer, Universidade Federal de Goiás, Brasil André Luiz Martins Lemos, Universidade Federal da Bahia, Brasil Angela Cristina Salgueiro Marques, Universidade Federal de Minas Gerais, Brasil Ângela Freire Prysthon, Universidade Federal de Pernambuco, Brasil Antonio Carlos Hohlfeldt, Pontifícia Universidade Católica do Rio Grande do Sul, Brasil Arthur Ituassu, Pontifícia Universidade Católica do Rio de Janeiro, Brasil

Bruno Campanella, Universidade Federal Fluminense, Brasil

Cláudio Novaes Pinto Coelho, Faculdade Cásper Líbero, Brasil Cárlida Emerim, Universidade Federal de Santa Catarina, Brasil Carlos Eduardo Franciscato, Universidade Federal de Sergipe, Brasil Danilo Rothberg, Universidade Estadual Paulista, Brasil Denise Tavares da Silva, Universidade Federal Fluminense, Brasil Diógenes Lycarião, Universidade Federal do Ceará, Brasil Eduardo Vicente, Universidade de São Paulo, Brasil Eliza Bachega Casadei, Escola Superior de Propaganda e Marketing - SP, Brasil Eneus Trindade, Universidade de São Paulo, Brasil

Erick Felinto de Oliveira, Universidade do Estado do Rio de Janeiro, Brasil Erly Vieira Júnior, Universidade Federal do Espírito Santo, Brasil Francisco de Assis, FIAM-FAAM Centro Universitário, Brasi

Francisco Elinaldo Teixeira, Universidade Estadual de Campinas, Brasil Francisco Gilson R. Pôrto Jr., Universidade Federal do Tocantins, Brasil Frederico de Mello Brandão Tavares, Universidade Federal de Ouro Preto, Brasil Gabriela Reinaldo, Universidade Federal do Ceará, Brasil Gilson Vieira Monteiro, Universidade Federal do Amazonas, Brasil Gustavo Daudt Fischer, Universidade do Vale do Rio dos Sinos, Brasi Itania Maria Mota Gomes, Universidade Federal da Bahia, Brasil Jiani Adriana Bonin, Universidade do Vale do Rio dos Sinos, Brasil José Afonso da Silva Junior, Universidade Federal de Pernambuco, Brasil José Luiz Aidar Prado, Pontifícia Universidade Católica de São Paulo, Brasil Josette Maria Monzani, Universidade Federal de São Carlos, Brasi Juçara Gorski Brittes, Universidade Federal de Ouro Preto, Brasil
Juliana Freire Gutmann, Universidade Federal da Bahia, Brasil Laura Loguercio Cánepa, Universidade Anhembi Morumbi, Brasil Leonel Azevedo de Aguiar, Pontifícia Universidade Católica do Rio de Janeiro, Brasil Letícia Cantarela Matheus, Universidade do Estado do Rio de Janeiro, Brasil Luciana Coutinho Souza, Universidade de Sorocaba, Brasil Maria Ataide Malcher, Universidade Federal do Pará, Brasil Maria Elisabete Antonioli, Escola Superior de Propaganda e Marketing - SP, Brasil Maria das Graças Pinto Coelho, Universidade Federal do Rio Grande do Norte, Brasil Marialva Carlos Barbosa, Universidade Federal do Rio de Janeiro, Brasil Marcel Vieira Barreto Silva, Universidade Federal da Paraíba, Brasil Marcia Tondato, Escola Superior de Propaganda e Marketing, Brasil Marli Santos, Universidade Metodista de São Paulo, Brasil

Márcio Souza Gonçalves, Universidade do Estado do Rio de Janeiro, Brasil Mauricio Mario Monteiro, Universidade Anhembi Morumbi, Brasil Mayka Castellano, Universidade Federal Fluminense, Brasil

Mozahir Salomão Bruck, Pontifícia Universidade Católica de Minas Gerais, Brasil Nísia Martins Rosario, Universidade Federal do Rio Grande do Sul, Brasil Paolo Demuru, Universidade Paulista, Brasil

Paula Melani Rocha, Universidade Estadual de Ponta Grossa, Brasil Potiguara Mendes Silveira Jr, Universidade Federal de Juiz de Fora, Brasil Priscila Ferreira Perazzo, Universidade Municipal de São Caetano do Sul, Brasil Rafael Cardoso Sampaio, Universidade Federal do Paraná, Brasil Rafael Tassi Teixeira, Universidade Tuiuti do Paraná, Brasil Regiane Lucas Garcês, Universidade Federal de Minas Gerais, Brasil Regiane Regina Ribeiro, Universidade Federal do Paraná, Brasil Renata Pitombo Cidreira, Universidade Federal do Recôncavo da Bahia, Brasil Renato Essenfelder, Escola Superior de Propaganda e Marketing, Brasil Roberto Elísio dos Santos, Universidade Municipal de São Caetano do Sul, Brasil Rodolfo Rorato Londero, Universidade Estadual de Londrina, Brasil Roseli Figaro, Universidade de São Paulo, Brasil

Simone Maria Andrade Pereira de Sá, Universidade Federal Fluminense, Brasi Sofia Cavalcanti Zanforlin, Universidade Católica de Brasília, Brasil Sônia Caldas Pessoa, Universidade Federal de Minas Gerais, Brasil Tatiana Oliveira Siciliano, Pontifícia Universidade Católica do Rio de Janeiro, Brasil Thaïs de Mendonça Jorge, Universidade de Brasília, Brasil

Valquiria Michela John, Universidade Federal do Paraná, Brasil

\section{CONSELHO CIENTÍFICO}

Cristiane Freitas Gutfreind, Pontifícia Universidade Católica do Rio Grande do Sul, Brasil I Eduardo Antônio de Jesus, Universidade Federal de Minhas Gerais, Brasil I Eduardo Morettin, Universidade de São Paulo, Brasil I Irene de Araújo Machado, Universidade de São Paulo, Brasil I Miriam de Souza Rossini, Universidade Federal do Rio Grande do Sul, Brasil

\section{COMISSÃO EDITORIAL}

Igor Pinto Sacramento, Universidade Federal do Rio de Janeiro, Brasil I Kelly Cristina de Souza Prudencio, Universidade Federal do Paraná, Brasil I Osmar Gonçalves dos Reis Filho, Universidade Federal do Ceará, Brasil I Rafael Grohmann, Faculdade Cásper Líbero, Brasil I Thaiane Moreira de Oliveira, Universidade Federal Fluminense, Brasil (editores associados)

\section{CONSULTORES AD HOC}

Afonso de Albuquerque, Universidade Federal Fluminense, Brasil I Cláudia Lago, Universidade de São Paulo, Brasil I Cesar Baio Santos, Universidade Federal do Ceará, Brasil I Eduardo Pellanda, Pontifícia Universidade Católica do Rio Grande do Sul, Brasi | Francisco Rüdiger, Pontifícia Universidade Católica do Rio Grande do Sul, Brasil | Karina Woitowicz, Universidade Estadual de Ponta Grossa, Brasil I Luis Mauro Sa Martino, Faculdade Cásper Líbero, Brasil I Norval Baitello Jr, Pontifícia Universidade Católica de São Paulo, Brasil | Pedro Guimarães, Universidade de Campinas, Brasil

\section{EQUIPE TÉCNICA}

ASSISTENTES EDITORIAIS Márcio Zanetti Negrini e Melina Santos । REVISÃO DE TEXTOS Fátima Áli | EDITORAÇ̃̃O ELETRÔNICA Roka Estúdio
COMPÓS I www.compos.org.br

Associação Nacional dos Programas de Pós-Graduação em Comunicação

Presidente

Marco Roxo

Programa de Pós-Graduação em Comunicação - UFF marcos-roxo@uol.com.br

Vice-Presidente

Isaltina Gomes

Programa de Pós-Graduação em Comunicação - UFPE

isaltina@gmail.com

Secretária-Geral

Gisela Castro

Programa de Pós-Graduação em Comunicação

e Práticas de Consumo - ESPM

castro.gisela@gmail.com

CONTATO I revistaecompos@gmail.com 